\title{
Machinability Evaluation of Titanium Alloys (Part 2) -Analyses of Cutting Force and Spindle Motor Current-
}

\author{
Masafumi KIKUCHI and Osamu OKUNO \\ Division of Dental Biomaterials, Graduate School of Dentistry, Tohoku University, 4-1 Seiryo-machi, Aoba-ku, Sendai, \\ Miyagi 980-8575, Japan \\ Corresponding author, E-mail:kikuchi@mail.tains.tohoku.ac.jp
}

Received September 28, 2004/Accepted November 12, 2004

\begin{abstract}
To establish a method of determining the machinability of dental materials for CAD/CAM systems, the machinability of titanium, two titanium alloys (Ti-6Al-4V and Ti-6Al-7Nb), and free-cutting brass was evaluated through cutting force and spindle motor current. The metals were slotted using a milling machine and square end mills at four cutting conditions. Both the static and dynamic components of the cutting force represented well the machinability of the metals tested: the machinability of Ti-6Al-4V and Ti-6Al-7Nb was worse than that of titanium, while that of free-cutting brass was better. On the other hand, the results indicated that the spindle motor current was not sensitive enough to detect the material difference among the titanium and its alloys.
\end{abstract}

Key words: Machinability, CAD/CAM, Titanium alloy

\section{INTRODUCTION}

Milling is the most commonly employed machining operation in dental CAD/CAM systems ${ }^{1)}$. It is a process whereby materials are shaped by removing unnecessary portions in the form of chips (swarf) using a rotary cutting tool. A so-called "cutting force" is required to remove chips from the workpiece, and it is known that the force has a close relationship with the mechanics of cutting ${ }^{2)}$.

The cutting force causes deflection of the machining system (workpiece, tool, and machine). Deflection adversely affects dimensional accuracy and surface finish. This phenomenon is of great concern in the field of dental milling because dental workpieces are generally thin, and consequently, have low stiffness. The use of miniature tools makes the deflection error even greater: the diameters of the end mills used for dental milling are, at most, a few millimeters. A high cutting force increases the stress on the cutting edges of the tool and promotes tool wear. It also increases repeated bending moment in the tool and causes fatigue fracture. It is obvious that extreme cutting force may slow or stop cutting. A lower cutting force, therefore, is generally desired for better machinability.

Measurements of the cutting force and torque have been performed in engineering, principally to investigate the cutting mechanism or to evaluate the machinability of a material ${ }^{2-4)}$. The measurements are utilized to develop free-cutting material or to select suitable cutting conditions (such as cutting speed, feed, and depth of cut). In addition, inprocess monitoring of the cutting force can be applied to the adaptive control of the cutting condition or to detect tool wear or breakage ${ }^{5,6)}$.

Although measurement of the cutting force is essential in machining research, it has seldom been performed in dentistry. For one reason, it has not been very long since dental $\mathrm{CAD} / \mathrm{CAM}$ systems came into practical use. For another, there are some differences between industrial and dental milling. Dental milling machines, tools, and workpieces are rather small compared to those of industrial milling. The work material used, such as titanium and its alloys, ceramics, or composites, may not be widely used in industry as a whole. In this second study, which follows our previous work ${ }^{7)}$, the dynamic component of cutting force and the spindle motor current were measured and analyzed as basic research to establish a method to evaluate the machinability of dental materials.

\section{MATERIALS AND METHODS}

\section{Specimen preparation}

The materials used in this study and their specifications are summarized in Table 1. Titanium buttons (15 $\mathrm{g}$ each) were made by melting titanium sponge (>99.8\%, grade S-90, Sumitomo Sitix, Amagasaki, Japan) in an argon-arc melting furnace (TAM-4S, Tachibana Riko, Sendai, Japan). After the chamber

Table 1 Materials used in this study

\begin{tabular}{ll}
\hline \multicolumn{1}{c}{ Metal (abbr.) } & Name, Manufacturer \\
\hline Titanium (Ti) & S-90, Sumitomo Sitix \\
Ti-6Al-4V (6Al4V) & DAT5, Daido Steel \\
Ti-6Al-7Nb (6Al7Nb) & T-Alloy Tough, GC \\
Brass & C3604, Kyoto Brass \\
\hline
\end{tabular}


Table 2 Cutting conditions

\begin{tabular}{ccccccc}
\hline \multirow{2}{*}{ Condition } & \multicolumn{2}{c}{ Cutting speed } & & \multicolumn{2}{c}{ Feed } & Depth of cut \\
\cline { 2 - 3 } & $\mathrm{rev} \cdot \mathrm{s}^{-1}$ & $\mathrm{~m} \cdot \mathrm{s}^{-1}$ & $\mathrm{~mm} \cdot \mathrm{s}^{-1}$ & $\mathrm{~mm} \cdot \mathrm{rev}^{-1}$ & $\mathrm{~mm}$ \\
\hline$(1)$ & 50 & 0.47 & 1 & 0.02 & 0.2 \\
$(2)$ & 50 & 0.47 & 1 & 0.02 & 0.4 \\
$(3)$ & 100 & 0.94 & 2 & 0.02 & 0.2 \\
$(4)$ & 100 & 0.94 & 2 & 0.02 & 0.4 \\
\hline
\end{tabular}

rev: revolution of cutting tool

was evacuated to $5 \mathrm{mPa}$, high-purity argon gas (>99.9999\%, Nippon Sanso, Kawasaki, Japan) was introduced until the pressure reached $50 \mathrm{kPa}$ for the melting atmosphere. In order to minimize gas absorption, a titanium getter was melted before melting the buttons. The top and bottom faces of the buttons were parallel-ground, producing specimens measuring approximately $23 \mathrm{~mm}$ in diameter and 8 $\mathrm{mm}$ in thickness.

Specimens $(25 \mathrm{~mm}$ in diameter and $6.5 \mathrm{~mm}$ in thickness) cut from wrought Ti-6Al-4V (annealed, DAT5, Daido Steel, Nagoya, Japan) and wrought Ti6Al-7Nb (annealed, T-Alloy Tough, GC, Tokyo, Japan) were also prepared. Specimens $(20 \mathrm{~mm}$ in diameter and $8 \mathrm{~mm}$ in thickness) cut from wrought free-cutting brass (as-fabricated, JIS H3250 C3604BDF, Kyoto Brass, Kyoto, Japan) were prepared as a representative free-cutting metal. All the surfaces subjected to cutting were polished with $\mathrm{SiC}$ abrasive paper down to 1000 grit. Six specimens were made for each metal.

\section{Cutting test}

The specimens were slotted using a computercontrolled milling machine (MDX-500, Roland DG, Hamamatsu, Japan) with a belt-drive spindle (ZS500T, Roland DG). A magnetic pickup (304-166, RS Components, Yokohama, Japan) installed close to the spindle and a digital tachometer (AC-962A-3, Asahi Keiki, Tokyo, Japan) were used to measure the rotational speed of the spindle. A three-orthogonal component force transducer (LSM-50KBS, Kyowa Electronic Instruments, Tokyo, Japan) was fixed on the table of the milling machine as a dynamometer. Three strain amplifiers (DPM-711B, Kyowa Electronic Instruments) were used for signal conditioning.

A current transformer (CT) (CTL-10-S50-30FCL2, U.R. D., Yokohama, Japan) was clamped to the commercial power input (single phase, $100 \mathrm{~V}, 50 \mathrm{~Hz}$ ) of the spindle motor driver circuit to measure the consumption of current. A resistor $(30 \Omega)$ was parallel-connected to the CT for current-to-voltage conversion. The output of the $\mathrm{CT}$ was amplified by a DC preamplifier (CA-206L2, NF, Yokohama, Japan).

Each specimen was gripped in a vise mounted on the transducer so that the surfaces to be cut on all specimens were even with the top of the vise. Carbide square end mills (TiAlN-coated, 2 flutes, mill diameter $3 \mathrm{~mm}$, FX-MG-EDS, OSG, Toyokawa, Japan) were used as the cutting tool. The axial direction of the tool was parallel to the $z$-axis (vertical axis) of the milling machine. The tool was fed in the $x$-axis direction of the machine. Testing was performed under four cutting conditions (Table 2) for each specimen. The tool was changed every three specimens. No cutting fluid or coolant was used.

While the specimen was being cut, the outputs of the three strain amplifiers and the preamplifier were acquired for $2^{14}$ data per channel at a sampling rate of $5 \mathrm{kHz}$ (approx. $3.3 \mathrm{~s}$ ) using a computer (AT-690C, Epson Direct, Matsumoto, Japan) equipped with a 16-bit A/D interface (PCI-6034E, National Instruments, Austin, TX, USA). The magnitude of the cutting force signal was characterized by two variables: static and dynamic components. The former is the average force of a particular span of time, while the latter is a component that changes with time. In the present study, they were defined as $F_{\text {static }}$ and $F_{\text {dynamic }}$ by the following equations:

$$
\begin{aligned}
& F_{\text {static }}=\frac{1}{N} \sum_{i=1}^{N} s_{i} \\
& F_{\text {dynamic }}=\sqrt{\frac{1}{N} \sum_{i=1}^{N}\left(s_{i}-F_{\text {static }}\right)^{2}}
\end{aligned}
$$

where $s$ is the time-series force data and $N$ is the number of data. As the equations suggest, $F_{\text {static }}$ and $F_{\text {dynamic }}$ are the mean and standard deviation of the data from a statistical point of view.

The root-mean-square of the current $I_{r m s}$ was calculated by the following equation:

$$
I_{r m s}=\sqrt{\frac{1}{N} \sum_{i=1}^{N} c_{i}^{2}}
$$

where $c$ is the time-series current data and $N$ is the number of data. Spindle motor current $I_{\text {spindle }}$ was determined by subtracting the idling current ( $I_{r m s}$ measured when the motor was not running) from the current measured during the test. 


\section{Statistical analysis}

Fourier analyses using $\mathrm{AC}$ coupling and a Hanning window were performed for the time-series force data. The cutting force and spindle motor current were analyzed using one-way ANOVA and the Scheffé's test at a significance level of $\alpha=0.05$. The strength of the relationship between the spindle motor current and the static component of the cutting force was examined by analysis of correlation.

\section{RESULTS}

\section{Linear spectrum of the cutting force signal}

An example of the Fourier analysis result of the cutting force signal is shown in Fig. 1. Although the intensity of the peaks varied with the test, almost all the frequencies of the major peaks corresponded to the frequencies that are integral multiples of the actual cutting speed $\left(51.5 \mathrm{rev} \cdot \mathrm{s}^{-1}\right.$ or $102.8 \mathrm{rev} \cdot \mathrm{s}^{-1}$ : approximately $3 \%$ higher than the desired values).

\section{Cutting force}

The dynamic components of the cutting force, $F_{\text {dynamic } \_x}, F_{\text {dynamic } y \text {, and }} F_{\text {dynamic } \_z}$, are shown in Fig. 2. The subscripts $\_, y$, and $z$ represent the $x$ (feed direction), $y$ (direction perpendicular to $x$ ), and $z$ (vertical downward direction) components of the force transducer (left-handed coordinate system). The direction of rotation of the cutting tool was from the positive $x$-axis to the negative $y$-axis. For the purposes of comparison, the figure also includes the static components, $F_{\text {static } x}, F_{\text {static } y}$, and $F_{\text {static } z}$ (expressed as $F_{x}, F_{y}$, and $F_{z}$, respectively), as in the previous study ${ }^{7}$. Although there were some exceptions, the magnitude relation of $F_{\text {dynamic }}$ was, on the whole, brass $<$ titanium $<$ Ti-6Al-7Nb and Ti-6Al-4V, as in the case of $F_{\text {static }}$ in absolute value. It is noteworthy that the value of $F_{d y n a m i c}$, as well as its standard deviation, was smaller for brass than for the other metals under all conditions.

$F_{\text {dynamic } x}$ for Ti-6Al-4V under cutting conditions (1) and (3) was significantly higher than that for titanium (both $p<0.05$ ) [Fig. $2(\mathrm{a})] . F_{\text {dynamic } x}$ for brass was a significantly lower value than that for titanium under all cutting conditions $[(1): p<0.01 ;(2)$ : $p<0.001 ;(3): p<0.01$; and $(4): p<0.001]$. The value for brass ranged from $45 \%$ to $70 \%$ of that for titanium. $\quad F_{\text {dynamic y }}$ for Ti-6Al-4V was significantly higher than that for titanium under conditions (1), (3), and (4) $(p<0.05, p<0.01$, and $p<0.01$, respectively) [Fig. $2(\mathrm{~b})] . \quad F_{\text {dynamic } y \text { for }}$ Ti-6Al-7Nb was significantly higher than that for titanium under cutting conditions (2) and (4) (both $p<0.05$ ). $F_{\text {dynamic } y}$ for brass was significantly lower than that for titanium under conditions (1), (2), and (4) ( $p$ $<0.01, p<0.001$, and $p<0.01$, respectively). $F_{\text {dynamic } z}$ for Ti-6Al-4V was significantly higher than that for titanium under all conditions $[(1): p<0.01 ;(2): p$

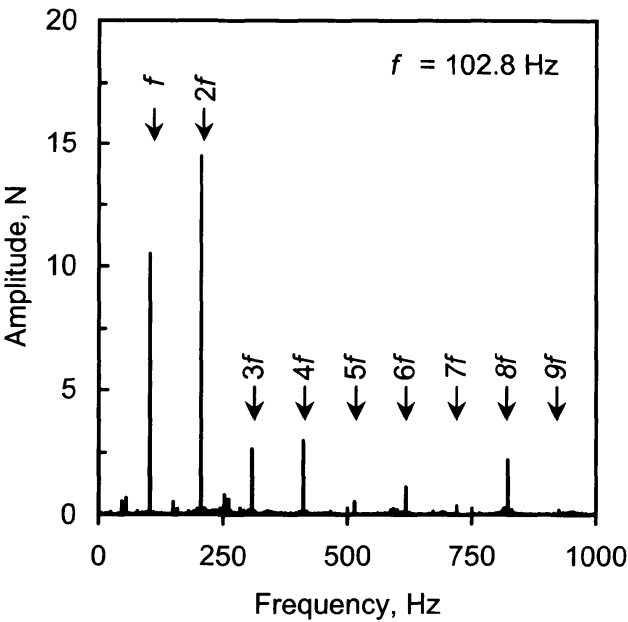

Fig. 1 An example of the linear spectrum of cutting force signal [Ti-6Al-4V, condition (4), $y$ component].

$<0.05$; (3): $p<0.01$; and (4): $p<0.001$ ] [Fig. 2(c)]. $F_{\text {dynamic } \_}$for Ti-6Al-7Nb was significantly higher than that for titanium under cutting condition (4) ( $p$ $<0.05)$. $\quad F_{\text {dynamic } z}$ for brass was significantly lower than that for titanium under condition $(2) \quad(p<0.05)$.

For each metal, there was an observed trend for $F_{\text {dynamic }}$ to increase as the cutting speed and feed, and the depth of cut increased although the trend was not always statistically significant. $F_{\text {dynamic }}$ was higher for condition (3) compared to condition (1), and for condition (4) compared to condition (2), while $F_{\text {static }}$ was almost the same for condition (3) compared to condition (1), and for condition (4) compared to condition (2). $F_{\text {static } x},-F_{\text {static } y}, F_{\text {dynamic } \_ \text {, }}$, $F_{\text {dynamic } y}$, and $F_{\text {dynamic } z}$ were higher for condition (2) compared to condition (1), and for condition (4) compared to condition (3).

\section{Spindle motor current}

Spindle motor current $I_{\text {spindle }}$ is shown in Fig. 3. For each metal, $I_{\text {spindle }}$ increased with the increase of the cutting speed and feed, and the depth of cut. The magnitude relationship among the cutting conditions was $(1)<(2)<(3)<(4)$. This relationship was statistically significant, except for those between (1) and (2) and between (3) and (4) of Ti-6 Al-7Nb.

The differences in current among the tested metals for each cutting condition were not as vast as those among the cutting conditions for each metal. For all conditions, $I_{\text {spindle }}$ for brass was lower than that for the other metals tested. The values for brass were significantly lower than that for titanium under conditions (3) and (4) $\quad(p<0.05$ and $p<0.01$, respectively). $I_{\text {spindle }}$ for $\mathrm{Ti}-6 \mathrm{Al}-4 \mathrm{~V}$ under condition (3) was also significantly lower than that for titanium $(p<0.05)$. This was the only case in which a significant difference in $I_{\text {spindle }}$ was observed among 

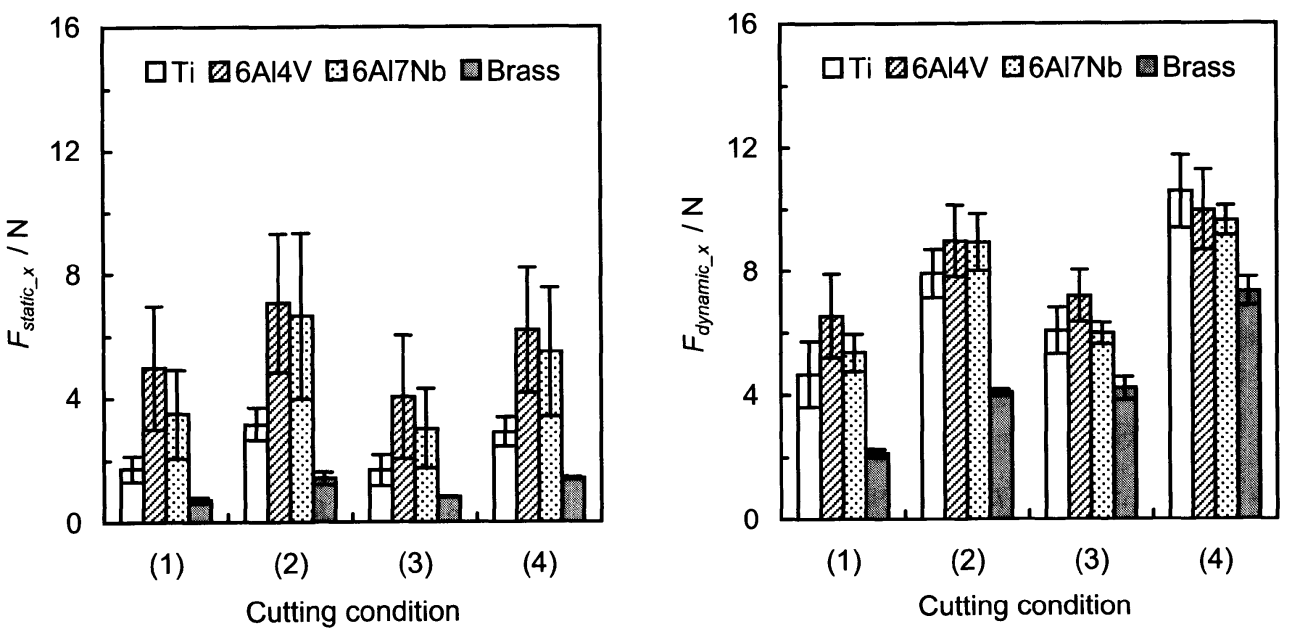

(a) $x$ component
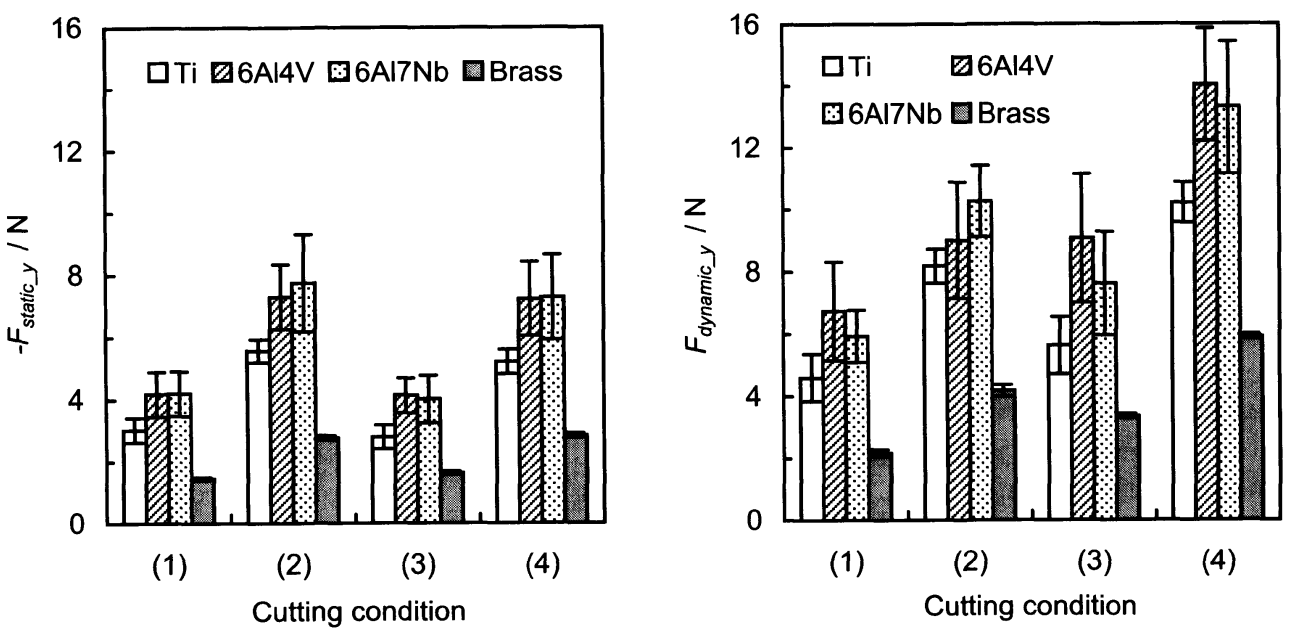

(b) y component
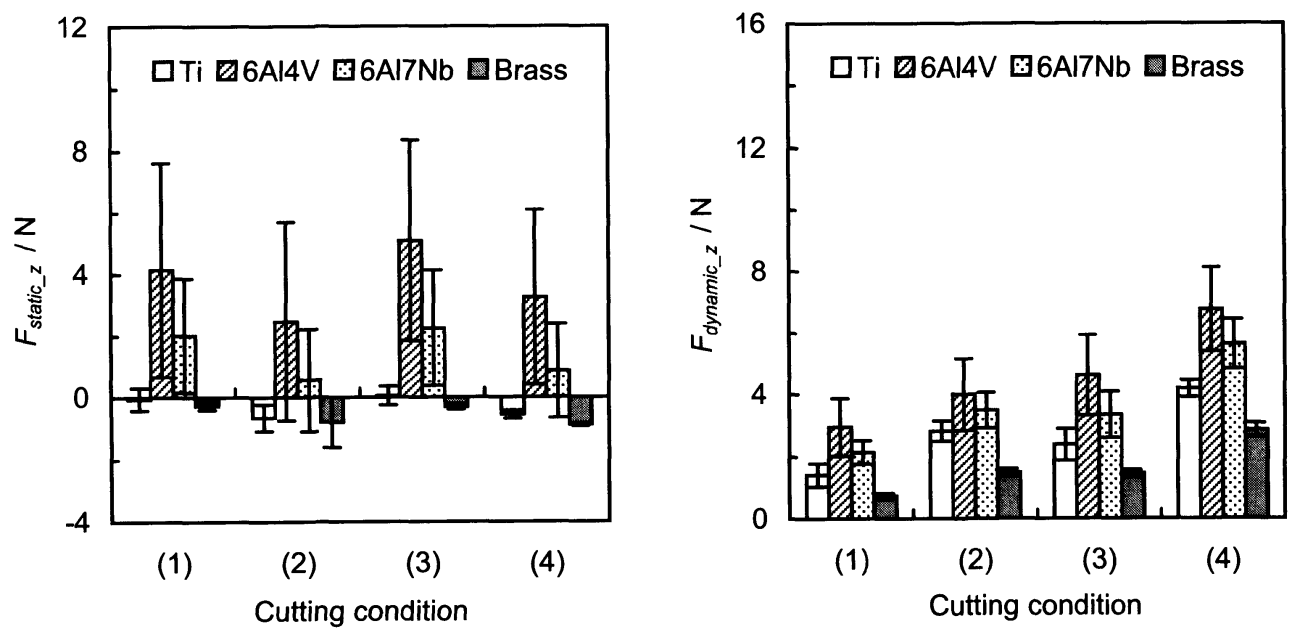

(c) $z$ component

Fig. 2 Static and dynamic components of the cutting force. Error bar: \pm SD 


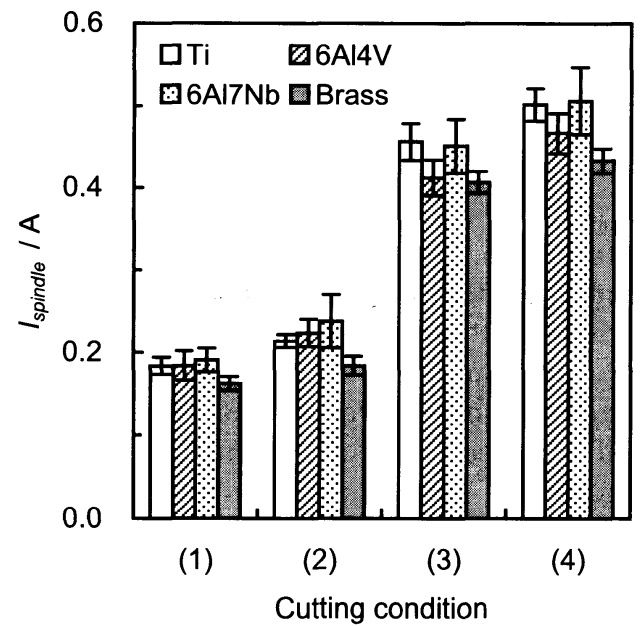

Fig. 3 Spindle motor current for the metals. Error bar: $\pm S D$

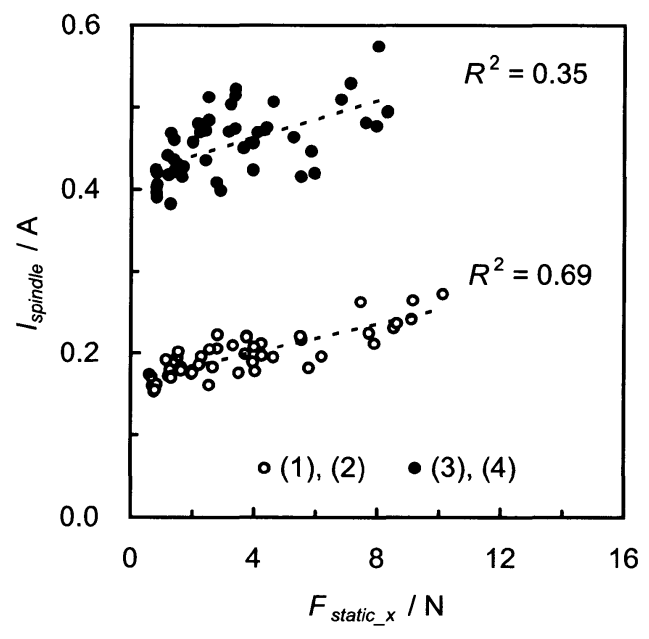

(a) $I_{\text {spindle }}$ vs. $F_{\text {static } \_x}$ the titanium and its alloys.

Relationship between spindle motor current and cutting force

The relationship between spindle motor current $I_{\text {spindle }}$ and the static component of cutting force $F_{\text {static }}$ is shown in Fig. 4. $I_{\text {spindle }}$ had a positive correlation with $F_{\text {static } x}$ and $-F_{\text {static_y }}$ (both horizontal forces), while there was no linear association with

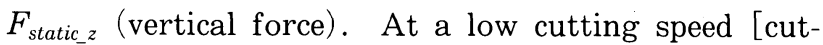
ting conditions (1) and (2)], $I_{\text {spindle }}$ had a very strong correlation with $F_{\text {static } y}\left(R^{2}=0.87\right)$ and a strong correlation with $F_{\text {static } x}\left(R^{2}=0.69\right)$. At a high cutting speed [cutting conditions (3) and (4)], $I_{\text {spindle }}$ had a strong correlation with $F_{\text {static } y}\left(R^{2}=0.55\right)$ and a weak correlation with $F_{\text {static } x}\left(R^{2}=0.35\right)$.

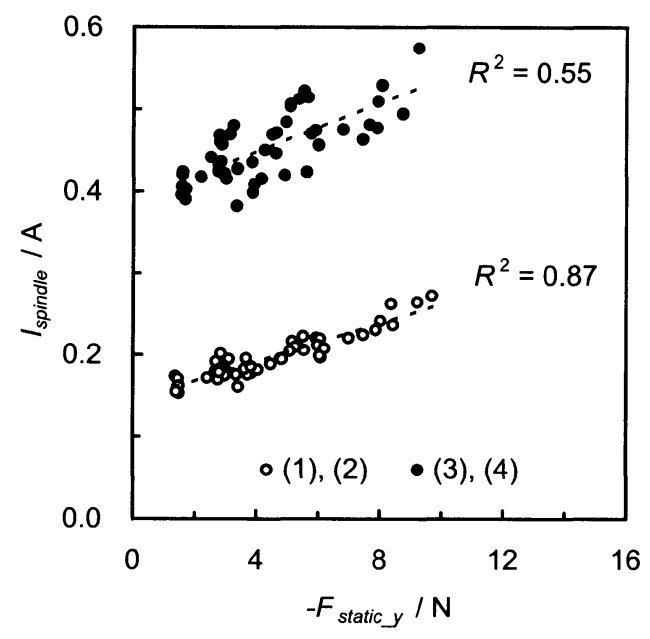

(b) $I_{\text {spindle }}$ vs. $F_{\text {static } y}$

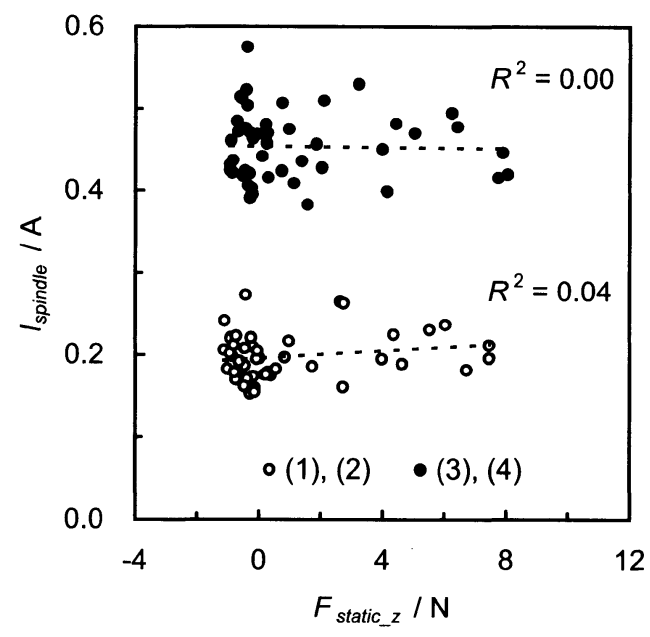

(c) $I_{\text {spindle }}$ vs. $F_{\text {static_z }}$

Fig. 4 Relationship between the spindle motor current and static component of the cutting force. 


\section{DISCUSSION}

\section{Cutting force}

Installing force transducers in commercial dental milling machines is difficult because of the limited space in the machines. However, it is definitely worthwhile to measure the cutting force using a general-purpose milling machine in order to develop a dental material with better machinability or to establish more suitable milling conditions.

A detailed discussion on the static component of the cutting force and its relationship with the properties of the metals tested is found in the previous study ${ }^{7)}$. The dynamic component of cutting force influences dimensional accuracy, surface finish, and tool life in the same way that the static component does because the dynamic component is superpositioned on the static component ${ }^{8,9)}$. Moreover, the dynamic component can cause significant vibration (chatter) and considerably influence surface finish when the dynamic stiffness of the cutting system is low ${ }^{10,11}$. The influence of the dynamic component cannot be ignored when its value is high. In fact, the values of the dynamic component were generally higher than the absolute values of the static component in the present study.

Judging from the results of the Fourier analyses, it can be safely said that the measured dynamic component of the cutting force was principally forced vibration that was excited by intermittent cutting, causing discontinuous chips with varying thickness to form as a result ${ }^{10)}$. It is known that the formation of inhomogeneous chips (so-called sawtooth chips), which is often the case with titanium or its alloys, also causes changes in the cutting force ${ }^{2,12,13)}$. Sawtooth chips involve short periodic shear, which causes ripples of force ${ }^{2,14)}$. However, considering the response speed of the measurement system, the component caused by sawtooth chip formation was scarcely recorded in the present study.

For each cutting condition, the magnitude relation of the dynamic component of the cutting force among the metals was similar to that of the static component. The absolute values of both the static and dynamic components for Ti-6Al-4V and Ti-6Al$7 \mathrm{Nb}$ were, on the whole, higher than those for titanium. This finding signified that the machinability of Ti-6Al-4V and Ti-6Al-7Nb was lower than that of titanium, in terms of cutting force. The superior machinability of free-cutting brass was evident from its lowest absolute values of both static and dynamic components (except for $F_{\text {static } z}$ ), compared to the other metals tested. The low standard deviations of the components indicated that the cutting state of free-cutting brass was steady. However, there were no significant differences in the surface roughness $\left(R_{a}\right.$ and $\left.R_{\max }\right)$ of the cut surfaces among the metals, and the influence of cutting force on surface rough- ness was not clear under the present conditons ${ }^{7)}$.

For each metal, the values of the dynamic and static components of horizontal cutting forces showed different trends among the cutting conditions. The absolute values of the $x$ and $y$ components of $F_{\text {static }}$ and $F_{\text {dynamic }}$ for all metals increased when the depth of cut increased. This result suggested that the absolute value of the horizontal cutting force positively correlated with the depth of cut. On the other hand, the absolute value of the static component of the cutting force did not increase when the cutting speed and feed increased, because the feed per revolution of the cutting tool $\left(\mathrm{mm} \cdot \mathrm{rev}^{-1}\right)$ was the same for all the cutting conditions ${ }^{15)}$. It would seem natural that the dynamic component of the cutting force would increase as the cutting speed and feed increased because of the higher impulsive force. In order to evaluate machinability properly through cutting force, it was therefore necessary to measure both the static and dynamic components.

\section{Spindle motor current}

In the present study, spindle motor current was measured as an alternative to the direct measurement of cutting torque. Torque detectors that can be attached to industrial milling machines are commercially available ${ }^{16)}$. However, they are usually difficult to apply to dental milling machines since this kind of spindle and tool is smaller and is used at a higher rotational speed than industrial spindles and tools. In industry, cutting torque or feed force is often estimated by measuring the motor current ${ }^{17-21)}$. Current sensors are relatively inexpensive and can be retrofitted without major machine modification, which is a great practical advantage. This method can be used when the driving current and output torque of the motor positively correlate. The DC brushless motor that drove the spindle of the milling machine in this study had such a correlation ${ }^{22)}$.

Although there was a slight difference between the desired and actual cutting speeds (rotational speed of spindle), it was barely affected by cutting, owing to the electronic regulation. An increase in current directly results in an increase in cutting power because the power is directly proportional to the product of torque and rotational speed. More cutting power is required to remove the material faster. Indeed, the current increased as the cutting speed and feed, and the depth of cut for each metal increased in the present study.

The spindle motor current positively correlated with the magnitudes of static horizontal cutting forces $\left(F_{\text {static } x}\right.$ and $\left.-F_{\text {static } y}\right)$. This correlation is reasonable because torque is defined as the product of lever arm length (radius of the cutting tool) and force perpendicular to the lever arm. The lower coefficients of correlation at high cutting speed than at low speed suggested an increase in deviation of both 
the current and the cutting force.

For each cutting condition, the current for brass was significantly lower than that for the other metals. However, the measurement of the current did not seem to be sensitive enough in the present study to detect the difference between the titanium and its alloys, even though there was a significant difference in the cutting force ${ }^{16,21)}$. It was probable that the difference in the current was not too high compared to the fluctuations caused by driver circuit, motor, or belt-drive spindle.

The current for Ti-6Al-4V was lower than that for titanium under conditions (3) and (4), while the machinability of Ti-6Al-4V was worse than that of titanium in terms of cutting force. Although it remains to be proved, a possible explanation for this finding is that the high vertical cutting force for Ti$6 \mathrm{Al}-4 \mathrm{~V}$, which reacted as the thrust force on the spindle, decreased the friction of the spindle and therefore reduced the spindle motor current at high speed.

\section{ACKNOWLEDGEMENTS}

The authors are extremely grateful to Sumitomo Sitix Co. Ltd. for providing the high-purity titanium sponge. The authors also gratefully acknowledge the GC Corporation for providing the titanium alloys. This study was partially supported by a Grant-inAid for Scientific Research (B) (2) No. 12470411 from the Japan Society for the Promotion of Science.

\section{REFERENCES}

1) CAD/CAM special. Quintessenz Zahntech 2001; 27: 9701080.

2) Shaw MC. Metal cutting principles, 2nd ed, Oxford University Press, New York, 2005, pp.15-44, 100-126, 544-572.

3) Strafford KN, Audy J. Indirect monitoring of machinability in carbon steels by measurement of cutting forces. J Mater Process Tech 1997; 67: 150-156.

4) Kahles JF, Field M, Eylon D, Froes FH. Machining of titanium alloys. J Metals 1985; 37: 27-35.

5) Tlusty J, Andrews GC. A critical review of sensors for unmanned machining. Annals CIRP 1983; 32: 563-572.

6) Dimla DE Snr. Sensor signals for tool-wear monitoring in metal cutting operations - A review of methods. Int J Machine Tools Manuf 2000; 40: 10731098.

7) Kikuchi M, Okuno O. Machinability evaluation of titanium alloys. Dent Mater J 2004; 23: 37-45.

8) Youn JW, Yang MY. A study on the relationships between static/dynamic cutting force components and tool wear. Trans ASME J Manuf Sci Eng 2001; 123: 196-205.

9) Toh CK. Static and dynamic cutting force analysis when high speed rough milling hardened steel. Mater Design 2004; 25: 41-50.

10) Hashimoto M, Marui E, Kato S. Experimental research on cutting force variation during primary chatter vibration occurring in plain milling operation. Int $\mathrm{J}$ Mach Tools Manuf 1996; 36: 183-201.

11) Ezugwu EO, Wang ZM. Titanium alloys and their machinability - A review. J Mater Process Tech 1997; 68: 262-274.

12) Komanduri $R$, von Turkovich BF. New observations on the mechanism of chip formation when machining titanium alloys. Wear 1981; 69: 179-188.

13) Komanduri R. Some clarifications on the mechanics of chip formation when machining titanium alloys. Wear 1982; 76: 15-34.

14) Vyas A, Shaw MC. Mechanics of saw-tooth chip formation in metal cutting. Trans ASME J Manuf Sci Eng 1999; 122: 163-172.

15) Tlusty J, MacNeil P. Dynamics of cutting force in end milling. Annals CIRP 1975; 24: 21-25.

16) Jemielniak K. Commercial tool condition monitoring systems. Int J Adv Manuf Tech 1999; 15: 711-721.

17) Mannan MA, Broms S. Monitoring and adaptive control of cutting process by means of motor power and current measurements. Annals CIRP 1989; 38: 347-350.

18) Stein JL, Wang CH. Analysis of power monitoring on AC induction drive systems. Trans ASME J Dynamic Systems Measurement Control 1990; 112: 239-248.

19) Altintas Y. Prediction of cutting forces and tool breakage in milling from feed drive current measurements. Trans ASME J Eng Industry 1992; 114: 386-392.

20) Kim GD, Chu CN. Indirect cutting force measurement considering frictional behaviour in a machining centre using feed motor current. Int J Adv Manuf Tech 1999; 15: 478-484.

21) Wu Y, Escande P, Du R. A new method for real-time tool condition monitoring in transfer machining stations. J Manuf Sci Eng 2001; 123: 339-347.

22) Kenjo T, Nagamori S. Brushless motors: Advanced theory and modern applications, Sogo Electronics Press, Tokyo, 2003, pp.109-146. 